\title{
A 7-year analysis of haemorrhage in patients on long-term anticoagulant treatment
}

\author{
J. C. FORFAR
}

From the Department of Cardiology, The Royal Infirmary of Edinburgh, Lauriston Place, Edinburgh

SUMMARY Anticoagulant treatment reduces the risk of embolic and thrombotic complications in certain patients but haemorrhagic problems of the treatment have been less critically assessed. In this study 501 fully documented outpatients treated between 1970 and 1977, comprising 1199 patient-years of treatment, have been analysed in an attempt to clarify the iatrogenic risks of haemorrhage associated with oral anticoagulants.

Forty-one patients experienced 51 haemorrhages of sufficient severity to seek medical advice. The incidence was 8.2 per cent among patients and 4.3 per cent per treatment year. There were 24 occasions when the haemorrhage was potentially lethal and 2 patients died. In 23 of these 24 events, the prothrombin ratio at the time of haemorrhage was prolonged beyond the therapeutic range. In contrast, the prothrombin ratio was only known to be prolonged beyond the therapeutic range on 1 of the 27 occasions with less serious haemorrhages.

The risk of haemorrhage was unrelated to age and was greatest in those patients in whom the prothrombin ratio had proved difficult to control from the outset and in men with an aortic valve prosthesis. There was no cumulative risk in the first 3 years of treatment but a trend for increased risk between 4 and 7 years. It is in these groups with a high risk of bleeding that prothrombin control and patient education call for the closest attention.

The coumarin group of anticoagulants was developed by Link in the late 1930's (Link, 1943-1944) and their use in man first reported by Butt et al. in 1941. Since then they have been used to reduce the risk of embolic and thrombotic complications in certain patients. Over the years the spectrum of disease for which long-term oral anticoagulation is recommended has widened (British Medical fournal, 1972; Rogers and Sherry, 1976; Staffurth et al., 1977). The therapeutic objective of achieving the lowest possible rate of thromboembolic complications must be weighed against the risk of haemorrhagic complications of therapy. The present study reviews the haemorrhagic complications of anticoagulation experienced in one anticoagulant clinic over a 7-year period.

\section{Series and methods}

In all, 509 outpatients attended between September 1970 and September 1977. Of these, 501 (242 men and 259 women) had case records available for

Received for publication 29 December 1978 examination-including 234 attending at the time the study was terminated-and form the basis of this analysis. Two hundred and forty-eight patients were interviewed personally. Four hundred and eighty patients $(96 \%)$ were maintained on warfarin and $21(4 \%)$ on dindevan. Prothrombin estimations (prothrombin ratio) were measured by the modified Quick test using British comparative thromboplastin (Dacie and Lewis, 1975). A case:control prothrombin ratio (PTR) between 1.8 and 2.6 to 1 was considered the desirable therapeutic range.

A significant haemorrhagic complication was defined as one in which a patient sought medical advice and received treatment, excepting minor bruising and minor epistaxes which are irregularly reported and therefore not included in this analysis. Significant haemorrhages were grouped into those episodes that were life-threatening (namely intracranial haemorrhage, haematemesis and melaena, and major retroperitoneal haemorrhage) and those which were not (see Table 2).

The probability of bleeding was calculated for each year-interval as the number of episodes of bleeding during each year-interval divided by the 
Table 1 Indications for anticoagulation

\begin{tabular}{lcc}
\hline Indication & \multicolumn{2}{l}{ Numbers } \\
\cline { 2 - 3 } & Men (\%) & Women (\%) \\
\hline Mitral valve disease/prosthesis & $62(12)$ & $171(34)$ \\
Aortic valve prosthesis & $45(9)$ & $22(4 \cdot 5)$ \\
Double or triple valve prosthesis & 2 & 5 \\
Ischaemic heart disease & $61(12)$ & 6 \\
DVT/pulmonary embolism & $40(8)$ & $31(6)$ \\
Atrial fibrillation/arterial embolism & 6 & 5 \\
Coronary artery bypass grafts & 11 & 2 \\
Cerebrovascular disease & 5 & 5 \\
Peripheral vascular disease & 3 & 5 \\
Others & 7 & 7 \\
Total & $242(48)$ & $259(52)$ \\
\hline
\end{tabular}

total number of years of exposure to anticoagulants during each year.

Table 1 gives details of the indications for anticoagulation. Valvular heart disease and a prosthesis were the commonest indications for long-term treatment accounting for 61 per cent of the series. The mean duration of treatment per patient was $2 \cdot 4$ years (range 1 month to 7 years) and, in all, 1199 patient-years of treatment were assessed. The mean age (and standard deviation) of men was $54 \cdot 3( \pm 9 \cdot 7)$ years and of women 55.3 $( \pm 10.6)$ years. A mean of 12.5 prothrombin estimations was measured per annum for each patient.

\section{Results}

\section{FREQUENCY OF HAEMORRHAGE}

Fifty-one significant haemorrhagic complications occurred in 41 patients, 24 in 19 men and 27 in 22 women. The overall incidence of haemorrhagic complications was thus 8.2 per cent among patients (501 patients; 41 patients haemorrhage) and 4.3 per cent per patient-treatment-year ( 51 haemorrhages in

Table 2 Sites of haemorrhage

\begin{tabular}{lc}
\hline Site & Number \\
\hline Life-threatening events & 1 \\
Intracerebral haemorrhage & 1 \\
Subarachnoid haemorrhage & 12 \\
Haematemesis and melaena & 6 \\
Retroperitoneal haematoma & \\
& \\
Other serious haemorrhages & 3 \\
Perinephric haematoma & 1 \\
Haemarthrosis & 6 \\
Haematuria & 5 \\
Muscle/skin haematoma & 2 \\
Retinal haemorrhage & 9 \\
Epistaxis & 1 \\
Haemoptysis & 3 \\
Menorrhagia & 1 \\
Mixed & 51 \\
Total & \\
\hline
\end{tabular}

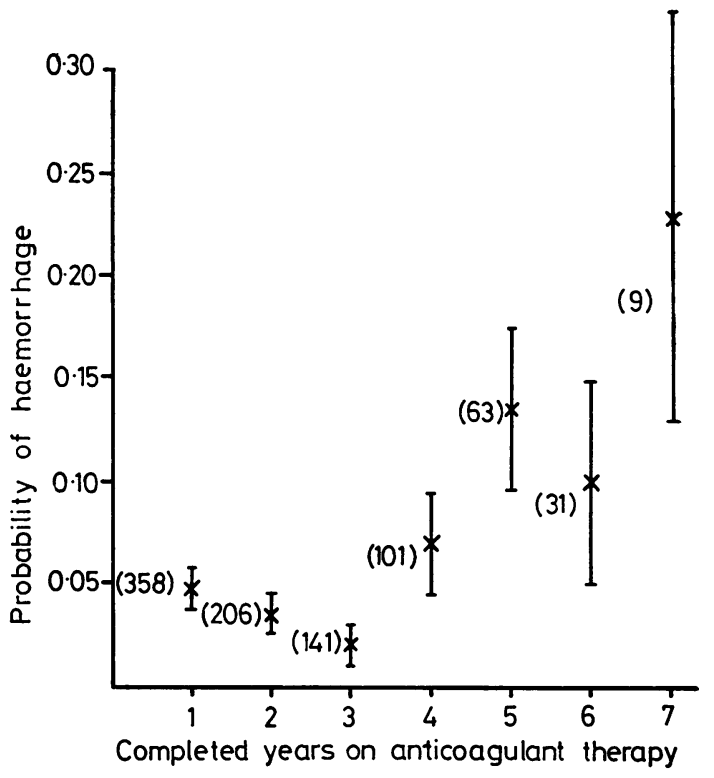

Fig. 1 Probability of haemorrhage related to duration of therapy.

1199 years) or 1 per 23 treatment-years. Sites of haemorrhage are detailed in Table 2 . The mean age of patients who bled was 47.8 ( \pm 11.5$)$ years for men and $53.6( \pm 10.6)$ years for women, neither significantly different from the means for patients who did not bleed: $54.9( \pm 9.5)$ for men and 55.4 $( \pm 10.5)$ for women. Forty-nine weeks of in-patient hospital care were required for the management of these patients, the mean duration of stay being just under 9 days.

The mean duration of anticoagulant treatment at the time of haemorrhage was $2 \cdot 4( \pm 2 \cdot 4)$ years for men and $2.9( \pm 2.1)$ years for women. To investigate whether anticoagulants had a durational effect, as far as the risk of haemorrhage was concerned, the probability of bleeding was calculated for each yearly interval for patients starting anticoagulants after 1970 (Fig. 1). There was no evidence of a cumulative effect over the first 3 years but some evidence of increasing risk between 4 and 7 years. Though the number of patient-years of treatment assessed for each year interval and shown in brackets decreases, the overall probability of haemorrhage in the first 3 years $(0.04 \pm 0.007)$ was less $(P<0.01)$ than the risk between 4 and 7 years $(0 \cdot 10 \pm 0 \cdot 025)$.

Two deaths were directly attributed to anticoagulants. One occurred in a 61-year-old woman (on warfarin for 10 months because of a mitral valve prosthesis) who became drowsy and later uncon- 


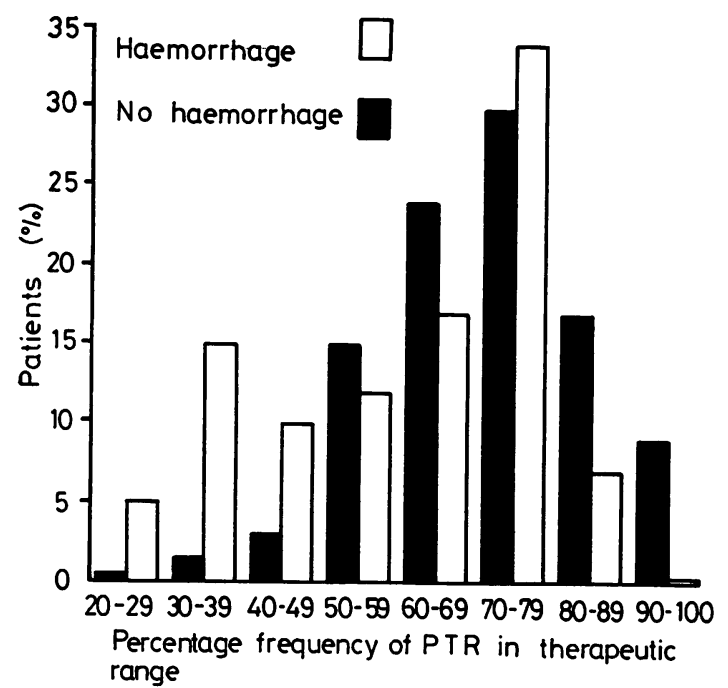

Fig. 2 Anticoagulant control.

scious 12 hours after hospital admission for observation of possible haematemesis. Prothrombin time on admission was $>120$ seconds with control time of 12 seconds (PTR > 10:1) and her condition deteriorated despite reversal of anticoagulation with parenteral factor concentrate (factors II, VII, IX, $\mathrm{X}$ ) and vitamin $\mathrm{K}_{1}(10 \mathrm{mg})$. Death occurred 72 hours after admission, necropsy showing extensive subarachnoid haemorrhage with no identifiable vascular abnormality. The other death occurred in a 43-year-old man (on warfarin for 2 years because of an aortic valve prosthesis) who became suddenly unconscious. His prothrombin ratio on admission was $3 \cdot 4: 1$. He was treated with parenteral vitamin $K_{1}$ (10 mg), but his condition deteriorated gradually, death occurring after 6 days from massive intracerebral haemorrhage with subarachnoid extension. Again, no vascular defect or occlusion was identified. In neither of these cases was the reason for the prolonged prothrombin ratio identified, ratios having been relatively stable in the weeks before admission. In both, platelet counts on admission were normal.

Table 3 Prothrombin ratio at time of haemorrhage

\begin{tabular}{llll}
\hline & $\begin{array}{l}\text { Within } \\
\text { therapeutic } \\
\text { range (\%) }\end{array}$ & $\begin{array}{l}\text { Beyond } \\
\text { therapeutic } \\
\text { range (\%) }\end{array}$ & Unknown (\%) \\
\hline Life threatening & $1(4)$ & $23(96)$ & 0 \\
Not life threatening & $22(81)$ & $1(4)$ & $4(15)$ \\
Total & $23(45)$ & $24(47)$ & $4(8)$ \\
\hline
\end{tabular}

ANTICOAGULANT CONTROL

The success of control of anticoagulant treatment was assessed for each patient as the number of prothrombin estimations within the therapeutic range expressed as a percentage of the total estimations performed on that patient. Fig. 2 shows the percentage frequency of prothrombin ratios within the therapeutic range for patients with and without haemorrhage plotted against the percentage of patients in each group. Control had been less good in those who bled, with higher percentages in the histograms to the left indicating poor control; 62.5 per cent of prothrombin estimations were within the therapeutic range in 'bleeders' compared with $70 \cdot 1$ per cent in 'non-bleeders', a highly significant difference $(P<0.001)$ in view of the large number of prothrombin ratios performed.

Table 3 shows the prothrombin ratios at the time of haemorrhage. Approximately half of all episodes occurred with the prothrombin ratio within the therapeutic range, but in 23 out of 24 episodes of life-threatening haemorrhage the prothrombin ratio was abnormally high. In contrast the prothrombin ratio was known to be prolonged beyond the therapeutic range in only 1 of the 27 occasions with less serious haemorrhage. Thus maintenance of the prothrombin ratio within the therapeutic range is almost always a protection against life-threatening haemorrhage but not less serious bleeding. Haemorrhage, however, did not always occur with an excessively prolonged prothrombin ratio. A prothrombin ratio greater than 3.4:1 was recorded overall in 2.5 per cent of patients who did not bleed.

In only $18(35 \%)$ out of the 51 haemorrhagic episodes was a probable contributory factor for haemorrhage identified (Table 4). Drug induced haemorrhage was common, with aspirin or aspirincontaining compounds the most frequent offenders. An intrinsic gastrointestinal lesion (Crohn's disease, small bowel polyp, gastric carcinoma, and duodenal ulcer) was identified in 4 out of the 12 episodes of gastrointestinal bleeding.

Table 4 Contributing factors in haemorrhage

\begin{tabular}{lc}
\hline Factor & $\begin{array}{l}\text { Number of } \\
\text { episodes }\end{array}$ \\
\hline Aspirin & 4 \\
Intrinsic GI lesion & 4 \\
Clerical error resulting in excess dosage & 2 \\
Phenylbutazone & 2 \\
Cotrimoxazole & 1 \\
Vancomycin & 1 \\
Ampicillin & 1 \\
Alcohol & 1 \\
Stopping barbiturate & 1 \\
Tetracycline & 1 \\
Total & 18 \\
\hline
\end{tabular}


Table 5 Specific management of haemorrhage

\begin{tabular}{lc}
\hline Treatment & $\begin{array}{c}\text { Number of } \\
\text { episodes }\end{array}$ \\
\hline No change in anticoagulant dosage & 16 \\
Reduction in dosage & 2 \\
Anticoagulant temporarily stopped & 13 \\
Anticoagulant stopped + vitamin $\mathrm{K}_{1}$ & 9 \\
Anticoagulant stopped + factor concentrate & 8 \\
Anticoagulant stopped permanently & 3 \\
Blood transfusion & 8 \\
Operative intervention & 8 \\
\hline
\end{tabular}

Specific measures in the management of haemorrhage are indicated in Table 5. Laparotomy was undertaken on 3 occasions for uncontrolled gastrointestinal bleeding after reversal of anticoagulant effect, and a lesion was identified at operation on 1 occasion. Nephrectomy was required twice for perinephric bleeding and cystoscopy on 3 occasions for haematuria.

\section{HAEMORRHAGE AND AORTIC VALVE \\ PROSTHESIS}

Of the 19 men who bled, $10(53 \%)$ had aortic valve prostheses compared with 223 non-bleeding men of whom $35(16 \%)$ had such prostheses $(P<0.01)$. The corresponding female figures were 22 bleeders with $3(14 \%)$ aortic valve prostheses and 237 nonbleeders with 19 prostheses (12.5\%) (NS). The reason for the increased risk of haemorrhage in men is unclear and has not been previously reported.

\section{Discussion}

During the 1950's the use of oral anticoagulants was more controversial than it is today (Gilchrist and Tulloch, 1956), but areas of controversy remain. Haemorrhage accounts for the majority of complications of treatment, and knowledge of its frequency is an important element in deciding on anticoagulant usage. Strict comparison between the results in different series is made difficult by differences in the technique of measuring prothrombin time and in the reporting of results, variation in the accepted therapeutic range between different centres (LamPo-Tang and Poller, 1975), and the need to take account of the duration of treatment. The problem is further compounded by different criteria adopted for definition of haemorrhage and the fact that the numbers of patients experiencing haemorrhage are not necessarily the same as the numbers of episodes of haemorrhage, since one patient may have more than one episode.

The incidence of haemorrhage has varied widely in reported series, in all of which the number of patient-years of treatment studied has been less than in the current series. Peyman in 1958 refers to studies where the incidence of haemorrhagic complications varied from a few to over 40 per cent. Pollard et al. in 1962 reported a high incidence of haemorrhage (47 out of 139 patients, or $34 \%$ ); 69 per cent of the bleeding episodes occurred with the prothrombin time in the therapeutic range, but 13 out of 14 episodes of major haemorrhage were associated with a prolonged prothrombin time. More recently, Husted and Andreasen (1976) found bleeding in 34 of 114 cases $(30 \%), 69$ per cent of these showing a prothrombin time in the therapeutic range at the time of bleeding. Coon and Willis (1974) found bleeding in 6.8 per cent of 3862 'courses' of oral and parenteral anticoagulant therapy. Among 217 patients maintained on oral anticoagulant therapy, Fleming and Bailey (1971) reported 1 death, $16(7.4 \%)$ major, and $18(8.3 \%)$ minor episodes of bleeding. Their survey covered a total of 649 patient-treatment-years giving a complication rate of 5.2 per cent per treatment-year. The series reported here shows an incidence of haemorrhage among the 501 patients of 8.2 per cent related to a mean duration of treatment of $2 \cdot 4$ years while the rate of haemorrhagic episodes calculated per treatment-year was 4.3 per cent. The results reported here support the view expressed by Pollard et al. that maintenance of the prothrombin ratio within the therapeutic range does not necessarily prevent haemorrhage, but protects against lifethreatening haemorrhage.

It seems unlikely that either of the deaths from intracranial haemorrhage could have been prevented. Fatal intracranial haemorrhage is rare (Coon and Willis, 1974), but is likely to be underestimated because of the difficulty in some instances of distinguishing clinically between cerebral embolism and cerebral haemorrhage. This emphasises the importance of a necropsy in all patients whose deaths occurred while they were on anticoagulants.

It is somewhat surprising that a clear contributory factor was identified in only 18 out of the 51 bleeding episodes. Aspirin related bleeding may have occurred more frequently than indicated because of its presence in a wide variety of commercial preparations. The rarity of antibiotic induced haemorrhage is interesting in view of the frequency of the prescription of these drugs in the population studied.

The lack of significant correlation between age and risk of bleeding differs from previous reports (Pollard et al., 1962; Coon and Willis, 1974). Age alters the clinical response to anticoagulants (O'Reilly and Aggeler, 1970; Hewick et al., 1975; 
Husted and Andreasen, 1977), either through a reduction in plasma protein binding or depression of hepatic synthesis of clotting factors. However, provided patient compliance and understanding are good and appropriate adjustments of dosage are made, age need not constitute a hazard in treatment and should not by itself be regarded as a contraindication to use.

Patients with valve prostheses consequent on rheumatic heart disease accounted for most of the group reported here. Such patients are at risk from periodic, sometimes prolonged, hepatic congestion which can profoundly impair drug catabolism and delay clotting factor synthesis (Hewick et al., 1975). This may in part explain the different responses to oral anticoagulants at different times in the same patient.

The use of factor concentrate (factors II, VII, IX, X) in the management of haemorrhage from excess oral anticoagulation has advantages over vitamin $\mathrm{K}_{1}$ (Taberner et al., 1976) and has been a significant advance in reducing the mortality and morbidity of these drugs. Factor concentrate has been freely available in this region for the past 3 or 4 years and allows immediate controlled reversal of anticoagulation without prejudicing later reintroduction of anticoagulant drugs.

Three groups of patients have been identified in whom the risk of haemorrhage is greatest. The first group are those patients in whom the prothrombin ratio has proved difficult to control from the outset; the second group are men with aortic valve prostheses, and the third are patients after 3 years on long-term treatment. Anticoagulants do carry a significant risk of haemorrhage and their long-term use in any patient should be based on firm evidence of efficacy. It is in the 3 groups mentioned that prothrombin control and patient education call for the closest attention, with frequent assessment of dosage. Patients with stable prothrombin ratios have a low risk of major bleeding and may be assessed less frequently.

I thank Dr R. M. Marquis for guidance and encouragement in the preparation of this analysis, Professor M. F. Oliver, Dr H. C. Miller, and Dr S. H. Davies for help with the manuscript, and $\mathrm{Mr}$ D. O. Forfar, F.F.A., for statistical advice.

\section{References}

British Medical fournal (1972). Editorial. Anticoagulants in mitral valve disease. 1,641 .

Butt, H. R., Allen, E. V., and Bollman, J. L. (1941). A preparation from spoiled sweet clover [3'3-methylene-bis-(4 hydroxycoumarin)] which prolongs coagulation and prothrombin time of the blood: preliminary report of experimental and clinical studies. Mayo Clinic Proceedings, 16, 388-395.

Coon, W. W., and Willis, P. W., III (1974). Hemorrhagic complications of anticoagulant therapy. Archives of Internal Medicine, 133, 386-392.

Dacie, J. V., and Lewis, S. M. (1975). Practical Haematology, 5 th edn. Churchill Livingstone, Edinburgh.

Fleming, H. A., and Bailey, S. M. (1971). Mitral valve disease, systemic embolism and anticoagulants. Postgraduate Medical fournal, 47, 599-604.

Gilchrist, A. R., and Tulloch, J. A. (1956). An evaluation of anticoagulant therapy in acute myocardial infarction. Scottish Medical fournal, 1, 1-14.

Hewick, D. S., Moreland, T. A., Shepherd, A. M. M., and Stevenson, I. H. (1975). The effect of age on the sensitivity to warfarin sodium (abstract). British Fournal of Clinical Pharmacology, 2, 189P-190P.

Husted, S., and Andreasen, F. (1976). Problems encountered in long term treatment with anticoagulants. Acta Medica Scandinavica, 200, 379-384.

Husted, S., and Andreasen, F. (1977). The influence of age on the response to anticoagulants. British fournal of Clinical Pharmacology, 4, 559-565.

Lam-Po-Tang, P. R. L. C., and Poller, L. (1975). Oral anticoagulant therapy and its control: an international survey. Thrombosis et Diathesis Haemorrhagica, 34, 419-425.

Link, K. P. (1943-1944). The anticoagulant from spoiled sweet clover hay. Harvey Lectures, 39, 162-216.

O'Reilly, R. A., and Aggeler, R. M. (1970). Determinants of the response to oral anticoagulants in man. Pharmacological Reviews, 22, 35-96.

Peyman, M. A. (1958). The significance of haemorrhage during the treatment of patients with the coumarin anticoagulants. Acta Medica Scandinavica, Suppl. 339, 1-62.

Pollard, J. W., Hamilton, H. J., Christensen, N. A., and Achor, W. P. (1962). Problems associated with long term anticoagulant therapy. Circulation, 25, 311-317.

Rogers, P. H., and Sherry, S. (1976). Current status of antithrombotic therapy in cardiovascular disease. Progress in Cardiovascular Diseases, 19, 235-253.

Staffurth, J. S., Gibberd, M. C., and Ng Tang Fui, S. (1977). Arterial embolism in thyrotoxicosis with atrial fibrillation. British Medical fournal, 2, 688-690.

Taberner, J. A., Thomson, J. M., and Poller, L. (1976). Comparison of prothrombin complex concentrate and vitamin $\mathrm{K}_{1}$ in oral anticoagulant reversal. British Medical fournal, 2, 83-85.

Requests for reprints to Dr J. C. Forfar, Department of Cardiology, The Royal Infirmary, Lauriston Place, Edinburgh EH3 9YW. 